OPEN ACCESS

Edited by:

Xiaoying $\mathrm{Li}$,

Capital Medical University, China

Reviewed by:

Osamu Nomura

Hirosaki University, Japan

Shujie Jia,

Capital Medical University, China

Hongsen Chen,

No. 1 People's Hospital of

Xiangshan, China

*Correspondence:

Ying Cui

arsenal13helb@zju.edu.cn

Specialty section

This article was submitted to

Intensive Care Medicine and

Anesthesiology,

a section of the journal

Frontiers in Medicine

Received: 30 June 2021 Accepted: 27 October 2021 Published: 26 November 2021

Citation:

Cui Y and Jiang S (2021) Influence of Personal Protective Equipment on the

Quality of Chest Compressions: A

Meta-Analysis of Randomized

Controlled Trials.

Front. Med. 8:733724.

doi: 10.3389/fmed.2021.733724

\section{Influence of Personal Protective Equipment on the Quality of Chest Compressions: A Meta-Analysis of Randomized Controlled Trials}

\author{
Ying Cui ${ }^{\star}$ and Siyi Jiang
}

Intensive Care Unit, The Fourth Affiliated Hospital Zhejiang University School of Medicine, Yiwu, China

Background: Randomized controlled trials (RCTs) evaluating the influence of personal protective equipment (PPE) on quality of chest compressions during cardiopulmonary resuscitation (CPR) showed inconsistent results. Accordingly, a meta-analysis was performed to provide an overview.

Methods: Relevant studies were obtained by search of Medline, Embase, and Cochrane's Library databases. A random-effect model incorporating the potential heterogeneity was used to pool the results.

Results: Six simulation-based RCTs were included. Overall, pooled results showed that there was no statistically significant difference between the rate [mean difference (MD): -1.70 time/min, 95\% confidence interval $(\mathrm{Cl}):-5.77$ to $2.36, P=0.41, R^{2}$ $=80 \%$ ] or the depth [MD: $-1.84 \mathrm{~mm}, 95 \% \mathrm{Cl}:-3.93$ to $0.24, P=0.11, R^{2}=$ $73 \%]$ of chest compressions performed by medical personnel with and without PPE. Subgroup analyses showed that use of PPE was associated with reduced rate of chest compressions in studies before COVID-19 (MD: -7.02 time/min, 95\% Cl: -10.46 to -3.57, $P<0.001$ ), but not in studies after COVID-19 (MD: 0.14 time/min, 95\% Cl: -5.77 to $2.36, P=0.95)$. In addition, PPE was not associated with significantly reduced depth of chest compressions in studies before (MD: $-3.34 \mathrm{~mm}, 95 \% \mathrm{Cl}:-10.29$ to $-3.62, P=0.35$ ) or after (MD: $-0.97 \mathrm{~mm}, 95 \% \mathrm{Cl}:-2.62$ to $0.68, P=0.25)$ COVID-19. No significant difference was found between parallel-group and crossover RCTs ( $P$ for subgroup difference both $>0.05$ ).

Conclusions: Evidence from simulation-based RCTs showed that use of PPE was not associated with reduced rate or depth of chest compressions in CPR.

Keywords: chest compressions, personal protective equipment, cardiopulmonary resuscitation, meta-analysis, randomized controlled trial, simulation studies

\section{INTRODUCTION}

High-quality cardiopulmonary resuscitation (CPR) is the most important life-saving procedure for people with critical clinical conditions, such as cardiac arrest (1-3). The success of CPR relies on effective chest compression, which is defined as compressions with adequate rate, depth, and minimized interruptions by the International Liaison Committee on Resuscitation (4). With the 
pandemic of coronavirus disease 2019 (COVID-19), increasing number of critically ill patients with COVID-19 need CPR (5). Since there is evidence for COVID-19 infection transmission during chest compressions, use of personal protective equipment (PPE) has been recommended for health care personnel involved in resuscitating of patients with confirmed or suspected COVID19 (6-8). However, studies evaluating the influence of PPE use on the quality of chest compression showed inconsistent results (9-14). Some simulation-based randomized controlled trials (RCTs) suggested that use of PPE by the CPR providers was associated with compromised quality of chest compression $(9,14)$, while others did not show significant difference regarding the performance of chest compression (10-13). An early metaanalysis including five studies (three RCTs and two observational studies) supported that the use of PPE may compromise the quality of chest compression during CPR (15). However, including observational studies may confound the results (15). Since three additional RCTs have been published since the metaanalysis (11-13), we performed an updated meta-analysis to provide an overview of current understanding regarding the influence of PPE use on quality of chest compression during the process of CPR.

\section{METHODS}

The PRISMA (Preferred Reporting Items for Systematic Reviews and Meta-Analyses) statement (16) and the Cochrane Handbook guidelines (17) were followed during the designing and implementation of the study.

\section{Search Strategy}

Medline, Embase, and the Cochrane Library (Cochrane Center Register of Controlled Trials) databases were searched for relevant studies with a combined strategy as [("personal protective equipment" OR "PPE”) AND (“chest compression" OR “cardiopulmonary resuscitation" OR "CPR")]. Animal studies were not considered. The references of related reviews and original articles were also searched as a complementation. The final database search was conducted on May 12, 2021.

\section{Study Selection}

Studies that fulfilled the following criteria were included: (1) studies published as full-length articles in English; (2) designed as simulation-based RCTs, either parallel group or crossover; (3) included medical personnel who were qualified to perform CPR and randomly allocated to perform chest compression with and

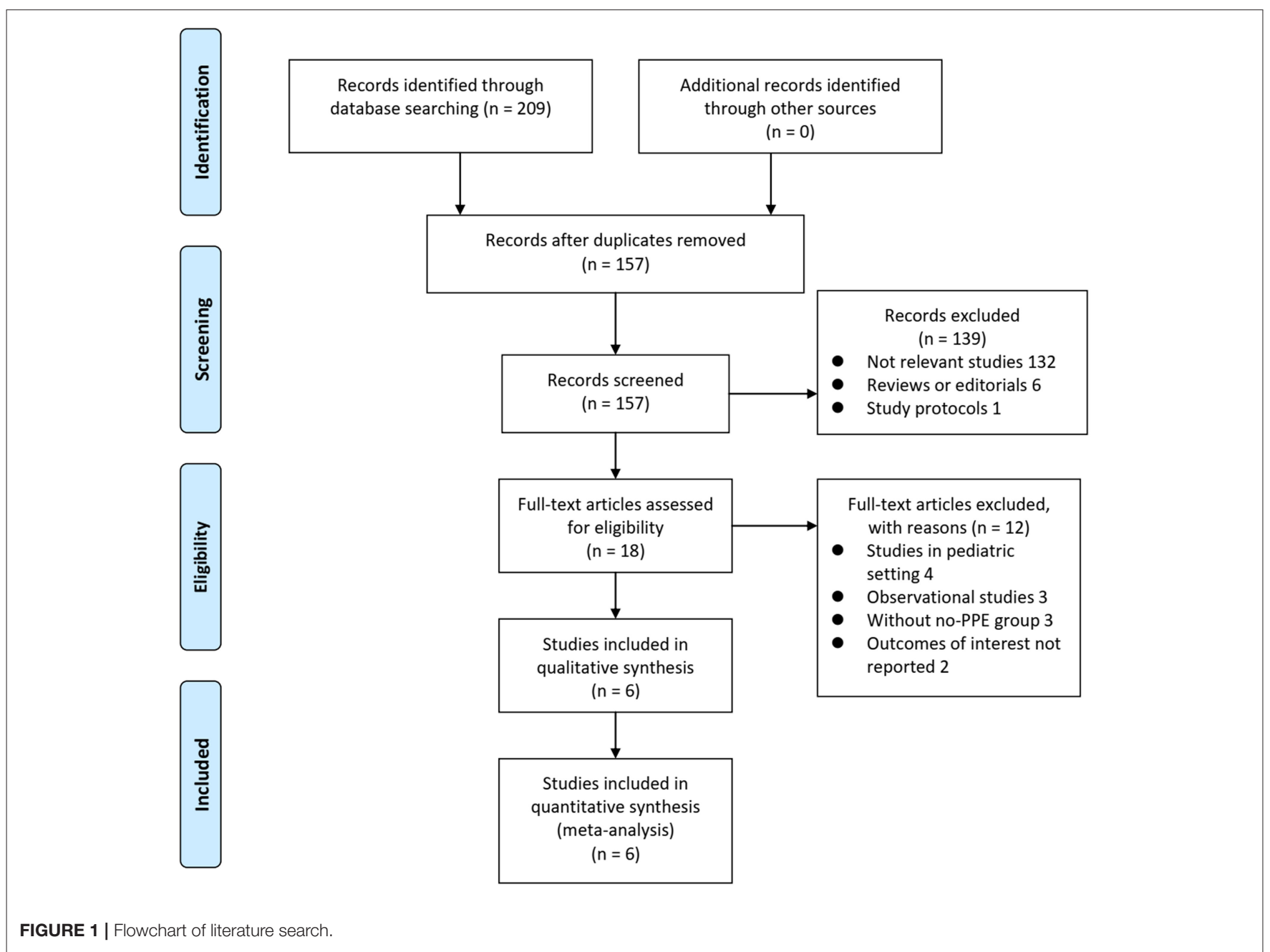


without the use of PPE; (4) only adult CPR studies were included; and (5) outcome regarding the quality of chest compression was reported, including the difference of rate and/or the depth of chest compression between the two groups. Reviews, editorials, study protocols, observational studies, and studies performed in pediatric settings were excluded.

\section{Data Extraction and Quality Assessment}

Database search, data extraction, and quality evaluation were conducted by two independent authors. If disagreement occurred, it was resolved by consensus. We extracted data regarding study information (first author, publication year, and study country), study design (blind or open-label), characteristics of medical personnel involved [sample size, age, sex, and body mass index (BMI)], details of PPE used, and durations for each cycle of chest compression. Quality evaluation was achieved using the Cochrane's Risk of Bias Tool (17) according to the following aspects: (1) random sequence generation; (2) allocation concealment; (3) blinding of participants and personnel; (4) blinding of outcome assessors; (5) incomplete outcome data; (6) selective outcome reporting; and (7) other potential bias.

\section{Statistical Analysis}

Differences of rate and/or the depth of chest compression between participants with and without the use of PPE were separately evaluated via mean difference (MD) and their 95\% confidence interval (CI) in this meta-analysis. We used the Cochrane's Q-test to detect the heterogeneity (18). The $I^{2}$ statistic was also calculated, and an $I^{2}>50 \%$ reflected significant heterogeneity. Pooled analyses were calculated using a randomeffect model because this method incorporates the influence of potential heterogeneity and retrieves a more generalized result (17). Sensitivity analysis by excluding one study at a time was used to evaluate the influence of each study on the pooled results of the meta-analysis (17). Subgroup analyses were performed to evaluate the results in studies published before or after the occurrence of COVID-19 and according to the design of the studies. We performed subgroup analysis according to the timing mainly because studies published after COVID-19 are

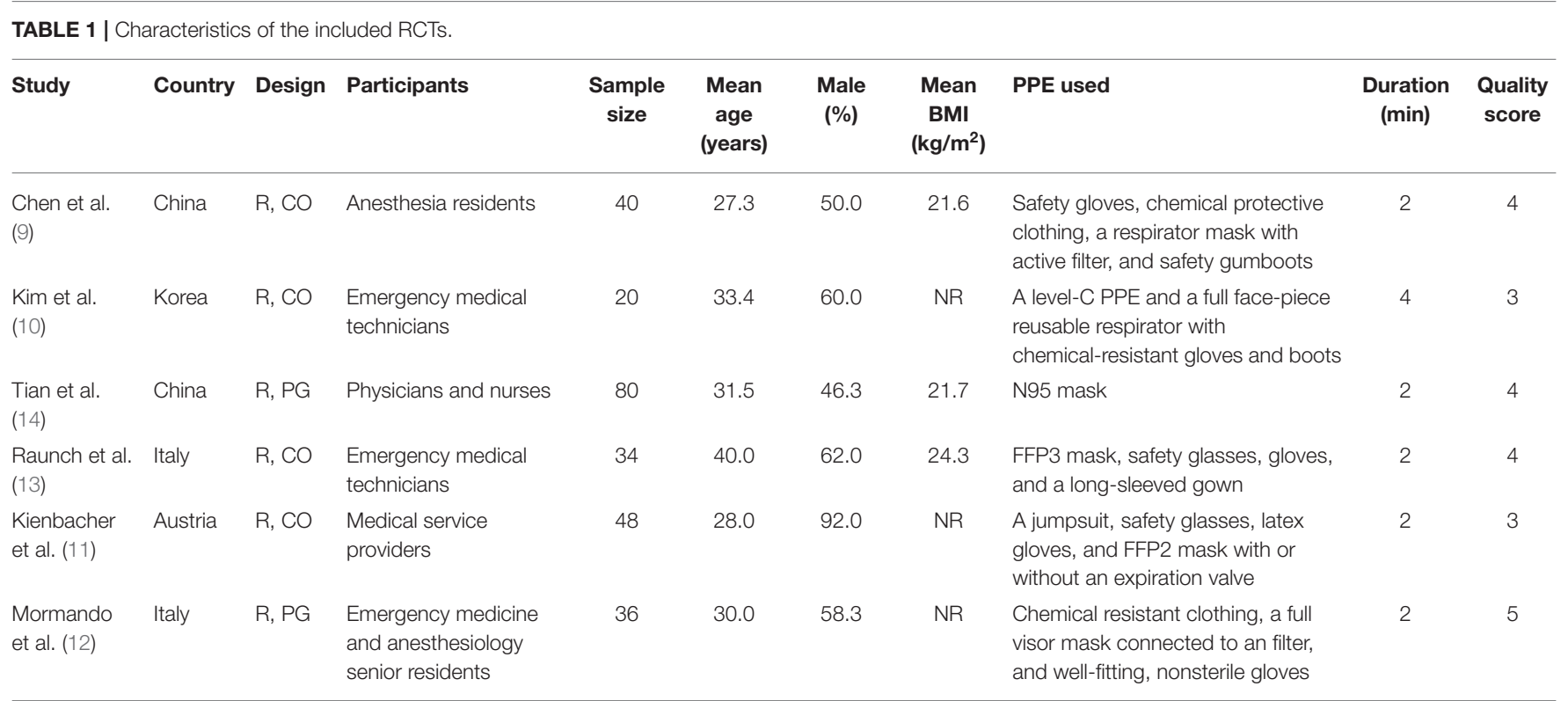

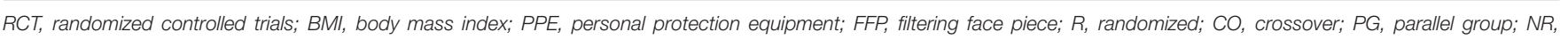
not reported.

TABLE 2 | Details of quality evaluation for the included RCTs via the Cochrane's Risk of Bias Tool.

\begin{tabular}{|c|c|c|c|c|c|c|c|c|}
\hline Study & $\begin{array}{l}\text { Random sequence } \\
\text { generation }\end{array}$ & $\begin{array}{l}\text { Allocation } \\
\text { concealment }\end{array}$ & $\begin{array}{l}\text { Blinding in } \\
\text { performance }\end{array}$ & $\begin{array}{l}\text { Blinding in outcome } \\
\text { detection }\end{array}$ & $\begin{array}{l}\text { Incomplete } \\
\text { outcome data }\end{array}$ & $\begin{array}{l}\text { Reporting } \\
\text { bias }\end{array}$ & Other bias & Total \\
\hline Chen et al. (9) & Low & Unclear & High & High & Low & Low & Low & 4 \\
\hline Kim et al. (10) & Unclear & Unclear & High & High & Low & Low & Low & 3 \\
\hline Tian et al. (14) & Low & Unclear & High & High & Low & Low & Low & 4 \\
\hline Raunch et al. (13) & Low & Unclear & High & High & Low & Low & Low & 4 \\
\hline Kienbacher et al. (11) & Unclear & Unclear & High & High & Low & Low & Low & 3 \\
\hline Mormando et al. (12) & Low & Low & High & High & Low & Low & Low & 5 \\
\hline
\end{tabular}

RCTs, randomized controlled trials. 
more likely to be designed for the chest compression under the circumstances of possible COVID-19 positive patients, which may be more meaningful considering the current pandemic of COVID-19. Publication bias was evaluated by visual inspection of funnel plots, and the Egger's regression asymmetry test (19). $P$-values $<0.05$ were considered statistically significant. The RevMan (Version 5.1; Cochrane, Oxford, UK) and Stata software (Version 12.0; Stata, College Station, TX) were applied for statistical analyses.

\section{RESULTS}

\section{Search Results}

The process of database search and study identification was shown in Figure 1. Briefly, 209 articles were obtained through the initial database search, and 157 were retrieved after exclusion of duplicated records. Among them, 139 articles were subsequently excluded based on titles and abstracts primarily because these studies were irrelevant to the aim of the meta-analysis. Of the 18

A

\begin{tabular}{|c|c|c|c|c|c|c|c|c|}
\hline \multirow[b]{2}{*}{ Study or Subgroup } & \multicolumn{3}{|c|}{ PPE } & \multicolumn{2}{|c|}{ No PPE } & \multirow[b]{2}{*}{ Total } & \multirow[b]{2}{*}{ Weight } & \multirow{2}{*}{$\begin{array}{l}\text { Mean Difference } \\
\text { IV, Random, } 95 \% \text { C }\end{array}$} \\
\hline & Mean & SD & Total & Mean & SD & & & \\
\hline \multicolumn{9}{|c|}{ 1.2.1 Before COVID-19 } \\
\hline Chen 2016 & 98.1 & 8.9 & 40 & 105.4 & 8.3 & 40 & $16.7 \%$ & $-7.30[-11.07,-3.53]$ \\
\hline Kim 2 & 112.2 & 13.4 & 20 & 117.8 & 13.8 & 20 & $10.6 \%$ & $2.83]$ \\
\hline Subtotal $(95 \% \mathrm{Cl})$ & & & 60 & & & 60 & & -7.0 \\
\hline \multirow{2}{*}{\multicolumn{9}{|c|}{$\begin{array}{l}\text { Heterogeneity: } \mathrm{Tau}^{2}=0.00 ; \mathrm{Chi}^{2}=0.13, \mathrm{df}=1(\mathrm{P}=0.72) ; \mathrm{I}^{2}=0 \% \\
\text { Test for overall effect: } \mathrm{Z}=3.99(\mathrm{P}<0.0001)\end{array}$}} \\
\hline & & & & & & & & \\
\hline \multicolumn{9}{|l|}{ 1.2.2 After COVID-19 } \\
\hline Tian 2020 & 107 & 16 & 40 & 118 & 16 & 40 & $12.3 \%$ & $-11.00[-1$ \\
\hline Rauch 2021 & 118 & 6 & 34 & 119 & 9 & 34 & $16.8 \%$ & $-1.00[-4$ \\
\hline Kienb & 118 & 8 & 48 & 116 & 7 & 24 & $16.9 \%$ & $0,5.60]$ \\
\hline Kienb & 118 & 6 & 48 & 116 & 7 & 24 & $17.3 \%$ & $2.00[-1.27,5.27]$ \\
\hline Mormando 2021 & 112 & 12.7 & 18 & 102 & 16.1 & 18 & $9.5 \%$ & $10.00[0.53,19.4]$ \\
\hline Subtotal $(95 \% \mathrm{Cl})$ & & & 188 & & & 140 & $72.7 \%$ & $0.14[-4.06,4.34$ \\
\hline
\end{tabular}

Heterogeneity: $\mathrm{Tau}^{2}=15.86 ; \mathrm{Chi}^{2}=16.32, \mathrm{df}=4(\mathrm{P}=0.003) ; \mathrm{I}^{2}=75 \%$

Test for overall effect: $Z=0.07(P=0.95)$

Total $(95 \% \mathrm{Cl})$

248

$200 \quad 100.0 \%$

Heterogeneity: $\mathrm{Tau}^{2}=22.16 ; \mathrm{Chi}^{2}=30.68, \mathrm{df}=6(\mathrm{P}<0.0001) ; \mathrm{I}^{2}=80 \%$

Test for overall effect: $Z=0.82(P=0.41)$

Test for subaroun differences: $\mathrm{Chi}^{2}=6.67 . \mathrm{df}=1(\mathrm{P}=0.010) . \mathrm{I}^{2}=85.0 \%$

$-1.70[-5.77,2.36]$

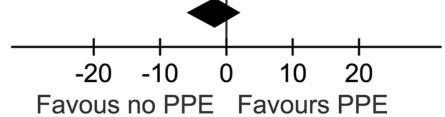

B

PPE

No PPE

Study or Subgroup Mean SD Total Mean SD Total Weight IV, Random, $95 \% \mathrm{CI}$ 1.4.1 Before COVID-19

\begin{tabular}{|c|c|c|c|c|c|}
\hline Chen 2016 & $42.5 \quad 6.8$ & 40 & $49.3 \quad 6.9$ & 40 & $14.5 \%$ \\
\hline $\begin{array}{l}\text { Kim } 2016 \\
\text { Subtotal }(95 \% \mathrm{Cl})\end{array}$ & $50.5 \quad 5.9$ & $\begin{array}{l}20 \\
60\end{array}$ & $50.2 \quad 6.1$ & $\begin{array}{l}20 \\
60\end{array}$ & $\begin{array}{l}12.5 \% \\
26.9 \%\end{array}$ \\
\hline
\end{tabular}

Test for overall effect: $Z=0.94(P=0.35)$

\subsubsection{After COVID-19}

Tian 2020

Rauch 2021

Kienbacher 2021a

Kienbacher 2021b

Mormando 2021

Subtotal $(95 \% \mathrm{Cl})$

$\begin{array}{rrr}47 & 9 & 40 \\ 54 & 6 & 34 \\ 56 & 4 & 48 \\ 56 & 4 & 48 \\ 52.2 & 7.7 & 18 \\ & & 188\end{array}$

$\begin{array}{rrrr}52 & 7 & 40 & 13.0 \% \\ 54 & 5 & 34 & 15.6 \% \\ 56 & 4 & 24 & 17.5 \% \\ 56 & 4 & 24 & 17.5 \% \\ 54.8 & 7.4 & 18 & 9.6 \% \\ & & 140 & 73.1 \%\end{array}$

Heterogeneity: $\mathrm{Tau}^{2}=1.58 ; \mathrm{Chi}^{2}=7.50, \mathrm{df}=4(\mathrm{P}=0.11) ; \mathrm{I}^{2}=47 \%$

Test for overall effect: $Z=1.15(P=0.25)$

Total $(95 \% \mathrm{Cl})$

\section{8}

$200 \quad 100.0 \%$

Heterogeneity: $\mathrm{Tau}^{2}=5.46 ; \mathrm{Chi}^{2}=22.40, \mathrm{df}=6(\mathrm{P}=0.001) ; \mathrm{I}^{2}=73 \%$

Test for overall effect: $Z=1.73(P=0.11)$

Test for subaroun differences: $\mathrm{Chi}^{2}=0.42 . \mathrm{df}=1(\mathrm{P}=0.52) . \mathrm{I}^{2}=0 \%$
Mean Difference

$-6.80[-9.80,-3.80]$

$0.30[-3.42,4.02]$

$-3.34[-10.29,3.62]$

$-5.00[-8.53,-1.47]$

$0.00[-2.63,2.63]$

$0.00[-1.96,1.96]$

$0.00[-1.96,1.96]$

$-2.60[-7.53,2.33]$

$-0.97[-2.62,0.68]$

Favous no PPE Favours PPE

FIGURE 2 | Forest plots for the meta-analysis of the quality of chest compression in medical personnel with and without PPE. (A) Forest plots for the meta-analysis of the rate of chest compression in studies before or after COVID-19 and (B) forest plots for the meta-analysis the depth of chest compression in studies before or after COVID-19. 
TABLE 3 | Sensitivity analyses.

\begin{tabular}{|c|c|c|c|c|}
\hline Dataset excluded & MD (95\% Cl) & $I^{2}(\%)$ & $P$ for Cochrane's $Q$-test & $P$ for overall effect \\
\hline \multicolumn{5}{|c|}{ Compression Rate (time/min) } \\
\hline Chen et al. (9) & $-0.54[-4.47,3.40]$ & 73 & 0.003 & 0.79 \\
\hline Kim et al. (10) & $-1.24[-5.63,3.16]$ & 83 & $<0.001$ & 0.58 \\
\hline Tian et al. (14) & $-0.45[-4.40,3.51]$ & 78 & $<0.001$ & 0.83 \\
\hline Raunch et al. (13) & $-1.84[-6.92,3.25]$ & 84 & $<0.001$ & 0.48 \\
\hline Kienbacher et al. (11) & $-2.44[-7.21,2.34]$ & 81 & $<0.001$ & 0.32 \\
\hline Kienbacher et al. (11) & $-2.46[-7.24,2.32]$ & 81 & $<0.001$ & 0.31 \\
\hline Mormando et al. (12) & $-2.86[-6.88,1.15]$ & 81 & $<0.001$ & 0.16 \\
\hline \multicolumn{5}{|c|}{ Compression Depth (mm) } \\
\hline Chen et al. (9) & $-0.76[-2.19,0.66]$ & 35 & 0.17 & 0.29 \\
\hline Kim et al. (10) & $-2.17[-4.50,0.16]$ & 77 & $<0.001$ & 0.07 \\
\hline Tian et al. (14) & $-1.36[-3.49,0.77]$ & 72 & 0.003 & 0.21 \\
\hline Raunch et al. (13) & $-2.21[-4.66,0.24]$ & 77 & $<0.001$ & 0.08 \\
\hline Kienbacher et al. (11) & $-2.26[-4.79,0.27]$ & 75 & $<0.001$ & 0.08 \\
\hline Kienbacher et al. (11) & $-2.26[-4.79,0.27]$ & 75 & $<0.001$ & 0.08 \\
\hline Mormando et al. (12) & $-1.78[-4.05,0.50]$ & 77 & $<0.001$ & 0.13 \\
\hline
\end{tabular}

$\mathrm{MD}$, mean difference; $\mathrm{Cl}$, confidence interval.

articles that underwent full-text review, 12 were further excluded for the reasons presented in Figure 1 Finally, six RCTs (9-14) were included.

\section{Study Characteristics}

Table 1 shows the characteristics of the included studies. Overall, these studies were all simulation-based RCTs including medical personnel who performed chest compression on a manikin with and without the use of PPE. Two of the studies were performed before the occurrence of COVID-19 $(9,10)$, while the other four were performed after COVID-19 (11-14). These RCTs were performed in China $(9,14)$, Korea (10), Italy $(12,13)$, and Austria (11). Four of them were randomized crossover studies $(9-11,13)$, while the remaining two were randomized parallel-group studies $(12,14)$. A total of 258 medical personnel who were qualified to perform CPR were involved in the included studies (mean age: 31.3 years, men: 60\%). Level-C PPE was used in five studies (913), and N95 mask was used in the other study (14). The levelC PPE applied among the included studies typically included safety gloves, safety glasses, chemical protective suits, respirator masks with active filter, and safety gumboots, etc., which have been specified for each study in Table 1. The duration of chest compression was $2 \mathrm{~min}$ in five studies $(9,11-14)$, and $4 \mathrm{~min}$ in the other study (10). Outcomes of rate and depth of chest compression between those with and without the use of PPE were reported in all of the included studies.

\section{Data Quality}

Table 2 shows the details of study quality evaluation. All of the included RCTs were open-label studies. Methods of random sequence generation were reported in four RCTs $(9,12-14)$, and information of allocation concealment was reported in one study (12). The overall quality score varied between 3 and 5, indicating moderate study quality.

\section{Meta-Analysis Results}

Since one study (11) reported data of caregivers who provided CPR with two different sets of PPE, PPE including a filtering face piece (FFP) 2 mask with valve, and with PPE including an FFP2 mask without valve, these datasets were independently included into the meta-analysis. Overall, pooled results of seven datasets from six RCTs showed that there was no significant difference in the rate (MD: -1.70 time/min, $95 \% \mathrm{CI}:-5.77$ to $2.36, P$ $=0.41, I^{2}=80 \%$; Figure $\left.2 \mathrm{~A}\right)$ or the depth (MD: $-1.84 \mathrm{~mm}$, 95\% CI: -3.93 to $0.24, P=0.11, I^{2}=73 \%$; Figure $2 B$ ) of chest compression between medical personnel with and without PPE. Sensitivity analyses by excluding one dataset at a time did not significantly change the results (MD for rate of chest compression: -2.86 to $-0.45, P$ all $>0.05$; $\mathrm{MD}$ for depth of chest compression: -2.26 to $-0.76, P$ all $>0.05$; Table 3 ). Specifically, sensitivity analysis limited to studies with level-C PPE (9-13) showed consistent result (chest compression rate: MD: -0.45 time/min, $95 \% \mathrm{CI}:-4.40$ to $3.51, P=0.83 ; I^{2}$ $=78 \%$; chest compression depth: $\mathrm{MD}:-1.36 \mathrm{~mm}, 95 \% \mathrm{CI}$ : 3.49 to $0.77, P=0.21 ; I^{2}=72 \%$; Table 3 ). Subgroup analyses showed that use of PPE was associated with reduced rate of chest compression in studies before COVID-19 (MD: -7.02 time/min, $95 \% \mathrm{CI}:-10.46$ to $-3.57, P<0.001$ ), but not in studies after COVID-19 (MD: $0.14 \mathrm{time} / \mathrm{min}, 95 \% \mathrm{CI}:-5.77$ to 2.36, $P=0.95$; Figure 2A). In addition, PPE was not associated with a significantly reduced depth of chest compression in studies before (MD: $-3.34 \mathrm{~mm}, 95 \% \mathrm{CI}:-10.29$ to $-3.62, P$ $=0.35)$ or after $(\mathrm{MD}:-0.97 \mathrm{~mm}, 95 \% \mathrm{CI}:-2.62$ to $0.68, P$ $=0.25$; Figure 2B) the occurrence of COVID-19. Moreover, subgroup analyses according to study design were shown in Figures 3A,B, which showed no significant between-subgroup differences of the rate or the depth of chest compression in parallel-group and crossover studies (both $P$ for subgroup difference $>0.05$ ). 


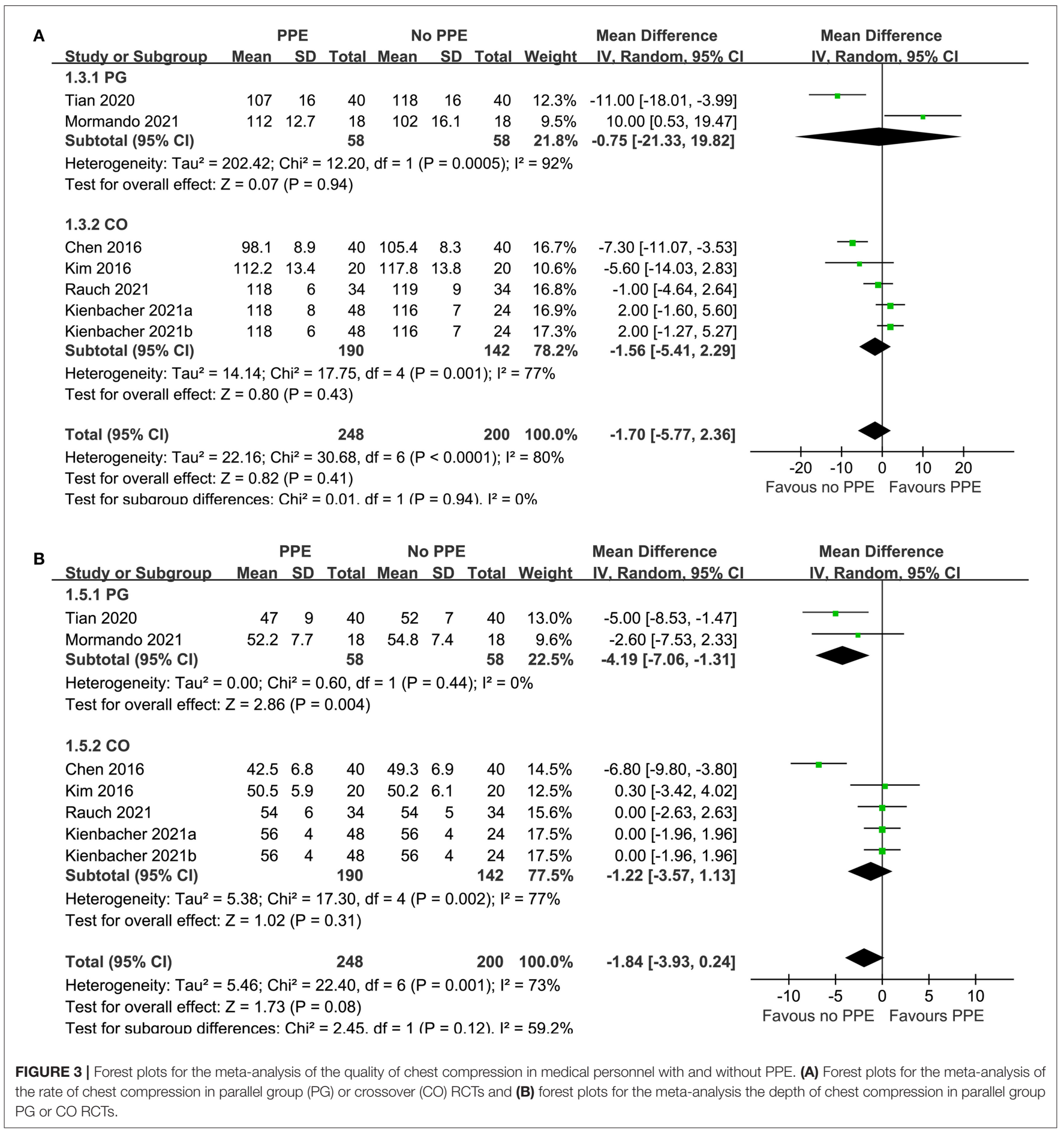

\section{Publication Bias}

The funnel plots for the meta-analysis of the rate and depth of chest compression between medical personnel with and without PPE were shown in Figures 4A,B. These funnel plots were symmetrical on visual inspection, suggesting low risk of publication biases. Egger's regression tests were not performed since only seven datasets were available for each outcome.

\section{DISCUSSION}

In this meta-analysis, by pooling the results of up-to-date simulation-based RCTs, we found that use of PPE was not associated with reduced rate or depth of chest compression in CPR. The robustness of the finding was confirmed by results of sensitivity analysis by excluding one dataset at a time. Moreover, subgroup analysis showed consistent results 


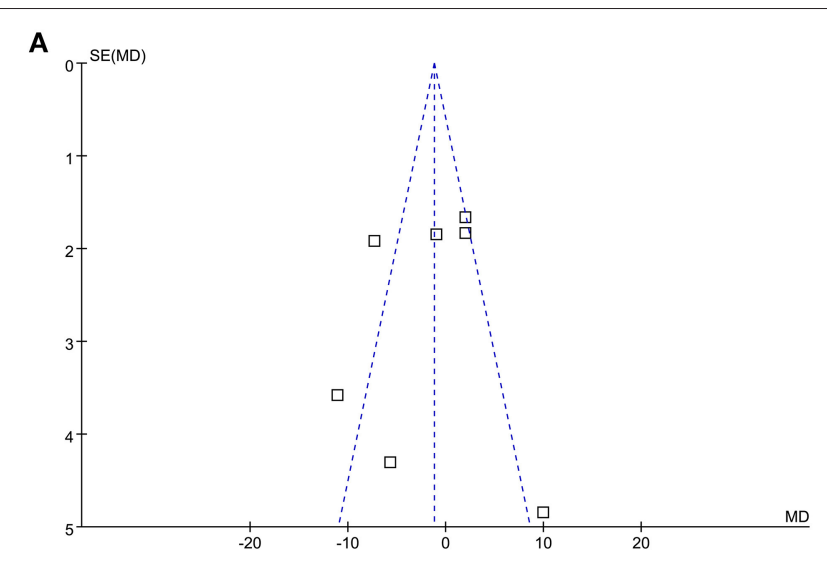

B

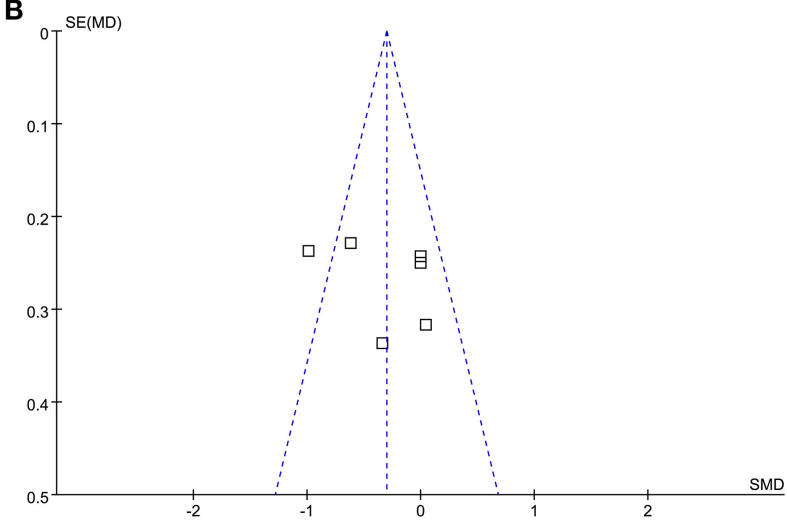

FIGURE 4 | Funnel plots for the meta-analysis of the quality of chest compression in medical personnel with and without PPE. (A) Funnel plots for the outcome of the rate of chest compression and (B) funnel plots for the outcome of the depth of chest compression.

for RCTs published after the occurrence of COVID-19. Taken together, these results suggest that PPE use in providers of CPR dose not compromise the quality of chest compression. Since there is evidence for COVID-19 infection transmission during chest compressions (6), results of this meta-analysis further supported the current recommendation that PPE should be worn during chest compressions for patients with confirmed or suspected COVID-19.

Results of our meta-analysis are different from the previous meta-analysis which showed that use of PPE may compromise the quality of chest compression during CPR (15). Some difference in methodology of meta-analysis should be noticed when the results of current meta-analysis and the previous one are compared. Firstly and the most importantly, although all of the included studies were simulation-based, the previous metaanalysis included both RCTs and observational studies (before and after PPE). Including the non-randomized before-and-afterPPE studies may confound the results of the overall meta-analysis since the procedures of chest compression with PPE were all performed after a few sessions without PPE (15). In our metaanalysis, only RCTs were included. Although four of the RCT included in our meta-analysis were crossover studies $(9-11,13)$, the sequences for performing chest compression with or without PPE were randomly allocated, which had minimized influence on the results. In addition, the previous meta-analysis included one study in the pediatric setting (15). Since the delivering of chest compressions to adult and pediatric patients is different, including study in the pediatric setting may also cause additional bias. Unlike the previous one, only RCTs of chest compressions performed in adult patients setting were included in our metaanalysis. Finally, only one out of the five included studies in the previous meta-analysis was performed during the COVID19 pandemic (15). In our meta-analysis four of the six included RCTs (11-14) were performed during the COVID-19 pandemic, and further subgroup analysis by including these four studies only also showed that use of PPE did not reduce the rate or depth of chest compressions in CPR. This is important because PPE used in these studies generally mimicked the PPE used in chest compressions for patients with suspected or confirmed COVID-19. Collectively, results of our meta-analysis suggest that use of PPE was not associated with reduced rate or depth of chest compressions in $\mathrm{CPR}$, and the results were consistent for including studies during the COVID-19 pandemic.

Evidence for optimal PPE during CPR is limited. One included RCT showed that PPEs including masks with and without expiration valve were both safe for use during CPR and did not significantly affect the quality of chest compressions (11). However, another non-randomized study showed that protective masks other than surgical masks used as PPE increase rescuer fatigue in CPR and negatively affect the quality of chest compressions (20). However, due to the non-randomized nature and lack of a control group without PPE, these results are difficult to interpret. Besides, automated chest compression devices and reduced duration of the cycle of CPR have also been suggested for patients with suspected or confirmed COVID-19 during CPR $(21,22)$. The optimal PPE may be that has minimized influence on the quality of chest compression, but has adequacy protection for the healthcare providers. More researches are needed for the development of an evidence-based CPR guideline for patients with COVID-19.

Our study has limitations. Firstly, the search strategy of this study was based on keywords, rather than using MeSH (Medline) and Emtree (EMBASE) as instructed by the Cochrane Handbook (17), and a librarian was not consulted during the development of the search strategy. Accordingly, search strategy in this study is not sufficient for a robust search. Besides, all of the included RCTs were simulation-based, and could not fully reflect the situation of real-life scenarios such as CPR for critically ill patients with COVID-19. In addition, the number of available studies and participants in each study are limited, which prevented comprehensive subgroup analysis according to the characteristics of the CPR providers and studies. Moreover, rate and depth were used to evaluate the quality of chest compressions during CPR. It remains unknown whether use of PPE may affect the clinical outcomes in patients receiving $\mathrm{CPR}$. Finally, significant heterogeneity was observed among the included studies. Although we found consistent results for studies during COVID-19 pandemic, future studies are needed to determine whether the difference in PPE may affect the results. 
In conclusion, results of the meta-analysis including simulation-based RCTs showed that use of PPE was not associated with reduced rate or depth of chest compressions in $\mathrm{CPR}$. These findings support the current recommendation that PPE should be worn during chest compressions for patients with confirmed or suspected COVID-19.

\section{DATA AVAILABILITY STATEMENT}

The original contributions presented in the study are included in the article/supplementary

\section{REFERENCES}

1. Harris AW, Kudenchuk PJ. Cardiopulmonary resuscitation: the science behind the hands. Heart. (2018) 104:105661. doi: 10.1136/heartjnl-2017-312696

2. Chalkias A, Ioannidis JPA. Interventions to improve cardiopulmonary resuscitation: a review of meta-analyses and future agenda. Crit Care. (2019) 23:210. doi: 10.1186/s13054-019-2495-5

3. Craig-Brangan KJ, Day MP. AHA update: BLS, ACLS, and PALS. Nursing. (2021) 51:24-30. doi: 10.1097/01.NURSE.0000754408.30786.72

4. Merchant RM, Topjian AA, Panchal AR, Cheng A, Aziz K, Berg KM, et al. Part 1: executive summary: 2020 american heart association guidelines for cardiopulmonary resuscitation and emergency cardiovascular care. Circulation. (2020) 142:S337-57. doi: 10.1161/CIR.0000000000000918

5. Ippolito M, Catalisano G, Marino C, Fuca R, Giarratano A, Baldi E, et al. Mortality after in-hospital cardiac arrest in patients with COVID19: a systematic review and meta-analysis. Resuscitation. (2021) 164:1229. doi: 10.1016/j.resuscitation.2021.04.025

6. Brown E, Chan LM. Should chest compressions be considered an aerosolgenerating procedure? A literature review in response to recent guidelines on personal protective equipment for patients with suspected COVID-19. Clin Med (Lond). (2020) 20:e154-9. doi: 10.7861/clinmed.2020-0258

7. Couper K, Taylor-Phillips S, Grove A, Freeman K, Osokogu O, Court R, et al. COVID-19 in cardiac arrest and infection risk to rescuers: a systematic review. Resuscitation. (2020) 151:59-66. doi: 10.1016/j.resuscitation.2020.04.022

8. Mudalige NL, Sze S, Oyefeso O, Koeckerling D, Barker J, Pan D. To PPE or not to PPE? Making sense of conflicting international recommendations for PPE during chest compressions in patients with COVID-19. Resuscitation. (2020) 156:146-8. doi: 10.1016/j.resuscitation.2020.09.019

9. Chen J, Lu KZ, Yi B, Chen Y. Chest compression with personal protective equipment during cardiopulmonary resuscitation: a randomized crossover simulation study. Medicine (Baltimore). (2016) 95:e3262. doi: 10.1097/MD.0000000000003262

10. Kim TH, Kim $\mathrm{CH}$, Shin SD, Haam S. Influence of personal protective equipment on the performance of life-saving interventions by emergency medical service personnel. Simulation. (2016) 92:893-8. doi: $10.1177 / 0037549716662322$

11. Kienbacher CL, Grafeneder J, Tscherny K, Krammel M, Fuhrmann V, Niederer $\mathrm{M}$, et al. The use of personal protection equipment does not impair the quality of cardiopulmonary resuscitation: a prospective triple-cross over randomised controlled non-inferiority trial. Resuscitation. (2021) 160:7983. doi: 10.1016/j.resuscitation.2021.01.021

12. Mormando G, Paganini M, Alexopoulos C, Savino S, Bortoli N, Pomiato $\mathrm{D}$, et al. Life-saving procedures performed while wearing cbrne personal protective equipment: a mannequin randomized trial. Simul Healthc Publish (2021). doi: 10.1097/SIH.0000000000000540. [Epub ahead of print].

13. Rauch S, Van Veelen MJ, Oberhammer R, Dal Cappello T, Roveri G, Gruber E, et al. Effect of wearing personal protective equipment (PPE) on CPR quality in times of the COVID-19 pandemic-a simulation, randomised crossover trial. $J$ Clin Med. (2021) 10:1728. doi: 10.3390/jcm10081728 material, further inquiries can be directed to the corresponding author/s.

\section{AUTHOR CONTRIBUTIONS}

YC and SJ conceived and designed the study, performed database search, study identification, data extraction, statistical analyses, and results interpretation. YC drafted the manuscript. Both authors revised the manuscript and approved the submission.
14. Tian Y, Tu X, Zhou X, Yu J, Luo S, Ma L, et al. Wearing a N95 mask increases rescuer's fatigue and decreases chest compression quality in simulated cardiopulmonary resuscitation. Am J Emerg Med. (2021) 44:4348. doi: 10.1016/j.ajem.2020.05.065

15. Sahu AK, Suresh S, Mathew R, Aggarwal P, Nayer J. Impact of personal protective equipment on the effectiveness of chest compression - a systematic review and meta-analysis. Am J Emerg Med. (2021) 39:1906. doi: 10.1016/j.ajem.2020.09.058

16. Moher D, Liberati A, Tetzlaff J, Altman DG. Preferred reporting items for systematic reviews and meta-analyses: the PRISMA statement. BMJ. (2009) 339:b2535. doi: 10.1136/bmj.b2535

17. Higgins J, Green S. Cochrane Handbook for Systematic Reviews of Interventions Version 6.2. The Cochrane Collaboration (2011). Available online at: https:// training.cochrane.org/handbook/current (accessed May 5, 2021).

18. Higgins JP, Thompson SG. Quantifying heterogeneity in a meta-analysis. Stat Med. (2002) 21:1539-58. doi: 10.1002/sim.1186

19. Egger M, Davey Smith G, Schneider M, Minder C. Bias in metaanalysis detected by a simple, graphical test. BMJ. (1997) 315:62934. doi: $10.1136 / \mathrm{bmj} .315 .7109 .629$

20. Serin S, Caglar B. The effect of different personal protective equipment masks on health care workers' cardiopulmonary resuscitation performance during the covid-19 pandemic. J Emerg Med. (2021) 60:292-8. doi: 10.1016/j.jemermed.2020.11.005

21. Malysz M, Dabrowski M, Bottiger BW, Smereka J, Kulak K, Szarpak A, et al. Resuscitation of the patient with suspected/confirmed COVID-19 when wearing personal protective equipment: a randomized multicenter crossover simulation trial. Cardiol J. (2020) 27:497-506. doi: 10.5603/CJ.a2020.0068

22. Malysz M, Smereka J, Jaguszewski M, Dabrowski M, Nadolny K, Ruetzler $\mathrm{K}$, et al. An optimal chest compression technique using personal protective equipment during resuscitation in the COVID-19 pandemic: a randomized crossover simulation study. Kardiol Pol. (2020) 78:125461. doi: $10.33963 /$ KP. 15643

Conflict of Interest: The authors declare that the research was conducted in the absence of any commercial or financial relationships that could be construed as a potential conflict of interest.

Publisher's Note: All claims expressed in this article are solely those of the authors and do not necessarily represent those of their affiliated organizations, or those of the publisher, the editors and the reviewers. Any product that may be evaluated in this article, or claim that may be made by its manufacturer, is not guaranteed or endorsed by the publisher.

Copyright $\odot 2021$ Cui and Jiang. This is an open-access article distributed under the terms of the Creative Commons Attribution License (CC BY). The use, distribution or reproduction in other forums is permitted, provided the original author $(s)$ and the copyright owner(s) are credited and that the original publication in this journal is cited, in accordance with accepted academic practice. No use, distribution or reproduction is permitted which does not comply with these terms. 